\title{
Infantile Renal Tubular Acidosis Due to Mercury Poisoning
}

\author{
PETER HUSBAND and W. J. D. MCKELLAR* \\ From the Department of Paediatrics, Charing Cross Group of Hospitals, Fulham Hospital, London
}

Husband, P., and McKellar, W. J. D. (1970). Archives of Disease in Childhood, 45, 264. Infantile renal tubular acidosis due to mercury poisoning. A 9month-old infant with renal tubular acidosis is reported. This illness followed the use of ammoniated mercury ointment for a napkin eruption. Raised levels of inorganic mercury were found in the urine. The patient was treated with alkalis, dimercaprol, and penicillamine. After 5 months, all therapy was discontinued and she has remained well.

Infantile renal tubular acidosis, first described by Lightwood (1935), was a common condition in this country until 1954 (Lightwood and Butler, 1963). Mercury poisoning has long been considered as a possible cause. The first suggestive evidence came from the case reported by MacGregor and Rayner (1964). The patient we report provides supportive evidence of mercury poisoning as a cause of renal tubular acidosis.

\section{Case Report}

A 9-month-old female infant was admitted to hospital because of weight loss for 7 weeks. She was the third child of healthy parents and was born after a normal pregnancy and delivery, birthweight $3.4 \mathrm{~kg}$. She had been breast-fed for 3 months and received no excess of vitamin D. She thrived well initially, weighing $7.5 \mathrm{~kg}$. at the age of 7 months (25th centile). She had frequently had a napkin rash from birth, and 9 weeks before admission this was treated with $2 \cdot 5 \%$ ammoniated mercury ointment obtained, without prescription, from a local chemist. This ointment was applied for 2 weeks at the end of which time the napkin rash had cleared, but then she developed an acute febrile illness lasting $\mathbf{4}$ days associated with a widespread morbilliform rash lasting 2 days, with painful gums. This was thought by her general practitioner to be rubella, and 2 weeks later her mother and two sisters developed a similar illness. From this time (aged 8 months) polyuria and anorexia were noted. Three weeks before admission she began to vomit, became constipated, and was lethargic. On admission to hospital her weight had fallen to $6 \cdot 8 \mathrm{~kg}$. (Fig. 1). On examination, she was a

\footnotetext{
Received 29 August 1969.

* Present address: Department of Paediatrics, Addenbrooke's Hospital, Cambridge.
}

fretful, wasted child with moderate dehydration. No other abnormal physical signs were found. BP $95 / 60 \overrightarrow{0}$ $\mathrm{mm} . \mathrm{Hg}$.

Investigations. Serum $\mathrm{Na} 140 \mathrm{mEq} / 1 ., \mathrm{K} \quad 4 \cdot 2 \mathrm{O}$ $\mathrm{mEq} / 1$. , Cl $116 \mathrm{mEq} / 1$. , and blood urea $32 \mathrm{mg} . / 100 \mathrm{ml}$. A capillary blood sample showed a metabolic acidosis $p \mathrm{H} 7 \cdot 28$, standard bicarbonate $13.5 \mathrm{mEq} / 1$., and $\mathrm{PCO}_{2} 21 \mathrm{~mm}$. Hg. The $p \mathrm{H}$ of freshly voided specimens

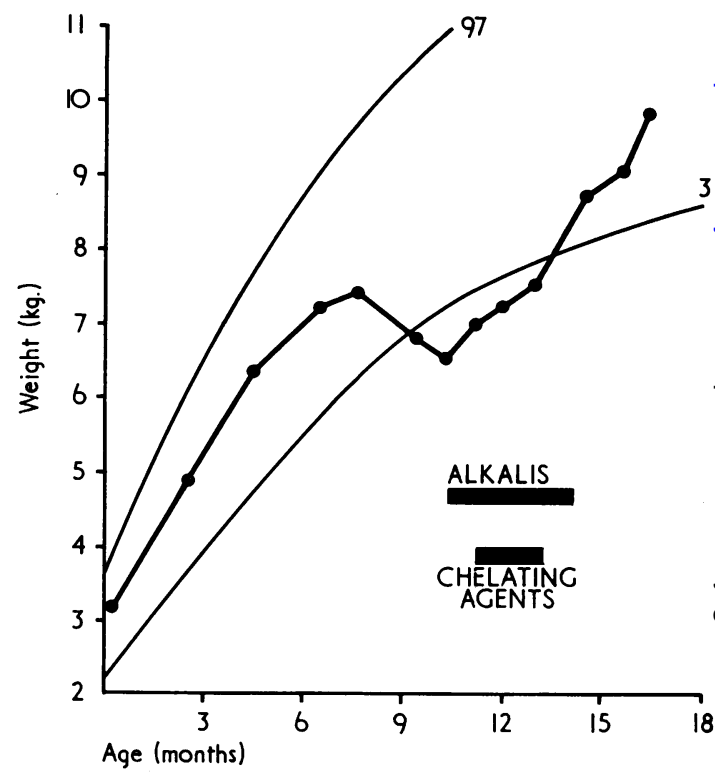

FIG. 1.-Chart showing weight gain during treatment with alkalis and chelating agents. 


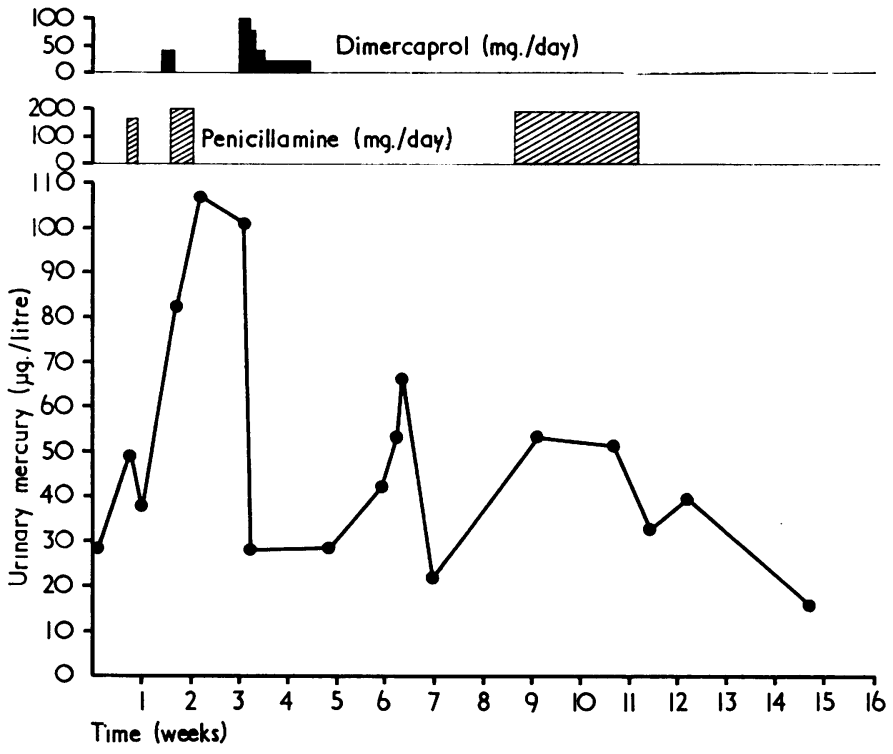

FIG. 2.-Urinary mercury excretion during treatment with chelating agents.

of urine at this time was $7 \cdot 27$ and 7.37. Serum calcium $8.7 \mathrm{mg} . / 100 \mathrm{ml}$., serum inorganic phosphate $5.2 \mathrm{mg} . / 100 \mathrm{ml}$., and alkaline phosphatase $10 \mathrm{KA}$ units. Plasma creatinine $0.5 \mathrm{mg} .100 \mathrm{ml}$. Urine showed no protein, no reducing substances, $3 \mathrm{WBC} / \mathrm{cu} . \mathrm{mm}$., and no growth on culture. Urinary amino acid chromatography was normal. Intravenous pyelogram was normal. Urinary mercury excretion was measured by the method of Magos and Cernik (1969) and corrected to a urinary specific gravity of $1 \cdot 016$. These results are shown in Fig. 2.

She was treated initially with a modified Albright's solution (sodium citrate $100 \mathrm{~g}$./1. and citric acid $60 \mathrm{~g}$./1.) $45 \mathrm{ml}$./day, increasing to $120 \mathrm{ml}$./day. This was not tolerated, and treatment was changed to sodium bicarbonate. Between 144 and $180 \mathrm{mEq}$ (12 to $15 \mathrm{~g}$.) per day were necessary to correct the acidosis. She was given courses of both dimercaprol and penicillamine, and during treatment the urinary inorganic mercury excretion rose to over $100 \mu \mathrm{g}$./1. (Fig. 2). As soon as treatment with alkalis was started she began to gain weight, thirst and polyuria ceased, and her stools became of normal consistency. Treatment with alkalis was discontinued after 5 months.

She has now been followed up for a further 6 months during which time the acidosis has not recurred. When aged 17 months an ammonium chloride test was performed. After an oral dose of $28 \mathrm{mEq}(1.5 \mathrm{~g}$.) the urinary $p H$ fell to $5 \cdot 8$, though the serum bicarbonate did not fall below $20 \mathrm{mEq} / 1$. At the same time the renal clearance of albumin/creatinine ratio was increased $\left(0.35 \times 10^{-3}\right)$, indicating increased glomerular permeability, and the renal clearance of lysozyme/creatinine was also raised $\left(11 \cdot 23 \times 10^{-3}\right)$, suggesting proximal tubular dysfunction. Creatinine clearance was $98 \cdot 8$ $\mathrm{ml}$./min. per $1 \cdot 73 \mathrm{sq} . \mathrm{m}$. Five weeks later the clearance of albumin/creatinine ratio was nearly normal $(0.006 \times$ $10^{-3}$ ) and the lysozyme excretion was also normal (Dr. T. M. Barratt).

\section{Discussion}

This patient showed the typical features of the self-limiting type of infantile renal tubular acidosis with an acute onset of anorexia, vomiting, constipation, polyuria, and weight loss in the first year of life, with subsequent recovery. Fig. 1 shows that her weight curve was normal until the age of 7 months when it fell to below the 3rd centile. The diagnosis of renal tubular acidosis was confirmed biochemically by the findings of a raised plasma chloride, low plasma bicarbonate, low blood $p \mathrm{H}$, and persistently alkaline urine.

Mercury poisoning was considered as a cause of acquired renal tubular acidosis by Lightwood and Butler (1963) because the incidence fell after the withdrawal of mercurial teething powders. In the first case reported by Lightwood, Payne, and Black (1953), a urinary mercury level of $47 \mu \mathrm{g}$./1. was recorded and the child was noted to have been given teething powders. In 16 out of 35 cases where accurate information was available the same authors stated that 7 children were known to have been given teething powders before the onset of symptoms, but in no case did they consider that an excess of mercury had been administered. Carré, 
Wood, and Smallwood (1954) reported a further 17 cases. Three children had been given teething powders and 2 children 'grey powders' containing mercurous chloride before the onset of symptoms. Five others had sore buttocks before the onset of symptoms. These authors commented that none of their cases was being completely breast fed at the time and they felt that, "it was possibly agents given to bottle fed babies because of their greater predisposition to gastro-intestinal upsets that were in some obscure way nephrotoxic'. They interpreted earlier authors' findings of traces of albumin or an excess of white cells in the urine with negative cultures as being consistent with a toxic or degenerative renal lesion. MacGregor and Rayner (1964) reported two sibs whose mother had used a mixture of 1 part calomel and 3 parts starch as a general dusting powder: the younger child developed renal tubular acidosis in 1959 at the age of 22 months; in 1964, the 7month-old sib presented with pink disease and was found to have a urinary mercury level of $500 \mu \mathrm{g}$. $/ \mathrm{l}$.

In the present case, the only known source of mercury to which the child was exposed was $100 \mathrm{~g}$. of ammoniated mercury ointment applied over 2 weeks to a raw, weeping napkin eruption. Ointment of ammoniated mercury (BP) is a $2.5 \% \mathrm{w} / \mathrm{w}$ ointment of mercuric ammonium chloride in a simple base consisting of equal parts of soft paraffin, beeswax, and lard wax. The base in which mercury is applied to the skin was shown to affect the absorption of mercury by Wild and Roberts (1926), who found that cutaneous absorption was greater from a lard base than from hydrous wool fat or paraffin bases. Laug et al. (1947) observed that mercury could be absorbed across intact skin. It is probably absorbed through the sweat pores and the hair follicles (Polson and Tattersall, 1959a). Absorption may be rapid, as shown by the development of acute poisoning within 24 hours (Mitchell, 1899). Robert (1946) found increased urinary mercury excretion for several months after the application of $10 \%$ ammoniated mercury ointment to both normal and ulcerated skins. Mercury absorption and poisoning after the therapeutic use of mercury containing ointment is well documented (Inman, Gordon, and Trinder, 1956; Young, 1960; Ross, 1964; Van Zeijst, Arends, and Mandema, 1964; Silverberg, McCall, and Hunt, 1967).

Mercury is a known renal poison. The more soluble mercuric salts are much more toxic to the kidneys than the mercurous salts, which in turn are more toxic than those organic mercurials which are used therapeutically as diuretics. After absorption, mercury is bound to circulating protein and is rapidly concentrated and stored in the renal cortex, especially in the proximal convoluted tubules. It is also deposited in the liver, muscles, and bones (Dathan, 1954; Polson and Tattersall, 1959b). $\stackrel{\text { S }}{9}$ Mercury has a specific affinity for sulphydryl groups, including those concerned with transport mechanisms across the renal tubular basement membrane $\frac{\bar{s}}{\sigma}$ (Kleinzeller and Cort, 1957). Burston, Darmady, $\stackrel{\mathbb{Q}}{\varrho}$ and Stranack (1958) showed that damage to the convoluted tubules, both proximal and distal, was $\rightarrow$ the salient feature of the acute nephrotoxicity of. mercury. By microdissection of nephrons, they $\vec{\omega}$ showed localized areas of cell necrosis and fatty ${ }^{\circ}$ degeneration. They felt that the absorptive function of the convoluted tubule raised the concentration? of mercury locally. In clinical studies of acutecr mercurial nephropathy necrosis of the distal portion of the proximal convoluted tubule is found. Calcification of the necrotic proximal tubular $\stackrel{\circ}{\oplus}$ epithelium occurs more commonly with mercury than other metals (Bruno, 1948). In the six cases of renal tubular acidosis reported by Lightwood $\vec{\nabla}$ (1935), calcification was seen in the collecting tubules. A nephrotic syndrome (Silverberg et al., 1967) and proteinuria (Young, 1960) have been $\vec{\ominus}$ described following the use of ammoniated mercury. ointment. The only evidence in the present case 8 of glomerular damage was the increased albumin/ creatinine clearance ratio.

Normal levels of mercury in the urine have been determined mainly in adults. Goldwater (1964) $\stackrel{\unrhd}{\complement}$ has shown that it is unusual for persons with no $\overrightarrow{\overrightarrow{0}}$ history of occupational exposure to mercury to 3 excrete more than $25 \mu \mathrm{g}$. $/ 1$. in the urine. In an analysis of 810 urine samples from many different countries, $79 \cdot 1 \%$ contained no detectable mercury and $97.5 \%$ of the samples contained less than $25 \mu \mathrm{g}$. of inorganic mercury/l. In 30 urine samples $\frac{0}{3}$ from this country, the range of mercury in the urine was from zero to $37.0 \mu \mathrm{g} . / 1 . ; 26$ of the $\delta$ specimens contained less than $0.5 \mu \mathrm{g} . / 1$. These findings are in agreement with Inman et al. (1956), 음 who found that subjects not previously known to $D$ have been exposed to mercury excreted $30 \mu \mathrm{g}$./1. or less, except for 2 subjects with urinary mercury N levels of 50 and $60 \mu \mathrm{g}$. $/ 1$., respectively. Some of the mercury which is excreted in the urine of $N$ healthy adults is derived from food. Stock $N$ (1926-40) and Gibbs, Pond, and Hansmann (1941) found measurable quantities present in practicallyo all foods. Mercury amalgam in dental fillings may $\bar{\varnothing}$ also contribute to the 'normal' urinary mercury $\stackrel{\infty}{+}$ excretion. As infants have a much less varied $\underline{T}$ diet than adults, it is reasonable to suppose that $\frac{O}{\mathbb{D}}$ they will excrete less mercury in the urine than is $\stackrel{\mathbb{D}}{\mathscr{P}}$ found in adults. Warkany and Hubbard (1948) 


\section{Infantile Renal Tubular Acidosis Due to Mercury Poisoning}

in a study of the association between pink disease and exposure to mercury found that no detectable mercury was present in the urine in $\mathbf{4 0}$ of 50 control cases. In 8 cases levels of up to $50 \mu \mathrm{g}$. $/ 1$. were found, but in 4 of these the level was $10 \mu \mathrm{g}$./1. which was near the limit of the error of their method; in a further 3 cases, no mercury was found in subsequent analysis and it was felt that the finding of mercury on the first occasion may have been due to contamination. In only 2 cases were levels of between 51 and $100 \mu \mathrm{g} . / 1$. recorded, and in one of these children there was a history of ingestion of calomel. Berenberg (1966) states that many consider any mercury in the urine abnormal, and that others regard any level above $10 \mu \mathrm{g}$./1. as pathological. We have measured the urinary mercury excretion on 10 occasions in 5 children of the same age as the patient but with no history of exposure to mercury, and the levels have ranged from less than $1 \mu \mathrm{g}$./1. to $4 \cdot 7 \mu \mathrm{g}$./l., with a mean value of $2 \mu \mathrm{g} . / 1$.

In our patient, the initial urinary inorganic mercury level of $30 \mu \mathrm{g} . / 1$. is thus almost certainly abnormally high. It is not, however, as high as levels reported in many cases of pink disease or in other cases of mercury intoxication. This may partly be explained by the route of administration. of the mercury and also because 3 months elapsed between the use of the ointment and the first urinary mercury estimation. Though no causal relation can be proved, the circumstantial evidence of mercury poisoning being the cause of this girl's illness is strong. Too much attention should not be paid to the actual level of mercury found in the urine of such patients. In the cases of psoriasis treated with ammoniated mercury ointment reported by Inman et al. (1956) no clinical evidence of poisoning or renal abnormality was found though high urinary mercury levels were observed. It has been shown in the past that there is no direct correlation between urinary mercury excretion and the severity of pink disease (Warkany and Hubbard, 1953). The same authors (1948) showed that after mercury ingestion children may excrete mercury in appreciable amounts in the urine without developing pink disease. This suggested to them an individual susceptibility or idiosyncracy to mercury. Ross (1964) described a 4-year-old boy with polyneuropathy after he had been treated for insect bites with ammoniated mercury ointment for 2 months. He felt the presence of eosinophilia supported the suggestion of an idiosyncracy to mercury. Black (1967) states that the nephrotic syndrome seen after absorption of mercury seems to be the result of an individual idiosyncracy.
Infantile renal tubular acidosis, treated only with alkalis, is known to be a self-limiting condition. Carré et al. (1954) discontinued alkali therapy after a mean time of 14 months, with a range of 3 to 33 months in a group of 12 children. Buchanan and Komrower (1958) were able to stop treatment in 7 out of 8 children, who presented between the ages of $3 \frac{1}{2}$ and 8 months, after periods of time varying from 5 to 23 months. The use of dimercaprol or penicillamine has not previously been reported in the treatment of renal tubular acidosis, but as it was possible to discontinue alkalis after 5 months' treatment, it is possible that the course of this illness was shortened by the use of these chelating agents. It appears from the weight chart (Fig. 1) that this patient's rate of weight gain accelerated once the urinary mercury levels had been lowered after treatment with these drugs.

Ammoniated mercury ointment is at present an unscheduled drug; thus, the ointment is easily obtained without prescription. In view of the findings presented in this paper and the previous published reports on the toxicity of mercury ointments, it seems desirable that it should become a scheduled poison obtainable only on a doctor's prescription. There does not, in any case, seem any justification for its use in paediatric practice.

We thank Dr. Hugh Jolly for allowing us to publish this case, the staff of the Medical Laboratory of H.M. Factory Inspectorate for the urinary mercury estimations, Dr. T. M. Barratt for the urinary lysozyme studies, and Prof. Wallace McCrory, Dr. H. Barrie, and Dr. Kinsey Smith for advice.

\section{REFERENCES}

Berenberg, W. (1966). Children's Medical Center, Boston. Clinical Pathological Conference. Acrodynia secondary to mercury intoxication. Fournal of Pediatrics, 68, 480.

Black, D. A. K. (1967). Renal Disease. 2nd. ed., p. 579. Blackwell, Oxford.

Bruno, M. S. (1948). Fatal toxic nephrosis following the administration of mercurial diuretics. New England fournal of Medicine, 239, 769.

Buchanan, E. U., and Komrower, G. M. (1958). The prognosis of idiopathic renal acidosis in infancy with observations on urine acidification and ammonia production in children. Archives of Disease in Childhood, 33, 532.

Burston, J., Darmady, E. M., and Stranack, F. (1958). Nephrosis due to mercurial diuretics. British Medical fournal, 1, 1277.

Carré, I. J., Wood, B. S. B., and Smallwood, W. C. (1954). Idiopathic renal acidosis in infancy. Archives of Disease in Childhood, 29, 326.

Dathan, J. G. (1954). Acrodynia associated with excessive intake of mercury. British Medical fournal, 1, 247.

Gibbs, O. S., Pond, H., and Hansmann, G. A. (1941). Toxicological studies on ammoniated mercury (Abstr.). Fournal of Pharmacology and Experimental Therapeutics, 72, 16.

Goldwater, L. J. (1964). The Harben Lectures, 1964. Occupational exposure to mercury. Fournal of the Royal Institute of Public Health, 27, 279.

Inman, P. M., Gordon, B., and Trinder, P. (1956). Mercury absorption and psoriasis. British Medical fournal, 2, 1202. 
Kleinzeller, A., and Cort, J. H. (1957). The mechanism of action of mercurial preparations on transport processes and the role of thiol groups in the cell membrane of renal tubular cells. Biochemical fournal, 67, 15.

Laug, E. P., Vos, E. A., Umberger, E. J., and Kunze, F. M. (1947). A method for the determination of cutaneous penetration of mercury. Fournal of Pharmacology and Experimental Therapeutics, 89, 42.

Lightwood, R. (1935). Calcium infarction of the kidneys in infants. Archives of Disease in Childhood, 10, 205.

- , and Butler, N. (1963). Decline in primary infantile renal acidosis: aetiological implications. British Medical fournal, $1,855$.

-, Payne, W. W., and Black, J. A. (1953). Infantile renal acidosis. Pediatrics, $12,628$.

Magos, L., and Cernik, A. A. (1969). A rapid method for estimating mercury in undigested biological samples. British fournal of Industrial Medicine, 26, 144.

MacGregor, M. E., and Rayner, P. H. W. (1964). Pink disease and primary renal tubular acidosis. A common cause. Lancet, 2 , 1083.

Mitchell, J. K. (1899). A case of mercurial poisoning. Fournal of Nervous and Mental Disease, 26, 505.

Polson, C. J., and Tattersall, R. N. (1959a). Clinical Toxicology, p. 215. English Universities Press, London.

, and - (1959b). Clinical Toxicology, p. 220. English Universities Press, London.

Robert, P. (1946). Klinische Untersuchungen über die Resorption der weissen Praecipitatsalbe durch die intakte Haut und durci产. ulceröse Wundflăchen. Dermatologica, 92, 85.

Ross, A. T. (1964). Mercuric polyneuropathy with albumino cytologic dissociation and eosinophilia. Fournal of the American Medical Association, 188, 830.

Silverberg, D. S., McCall, J. T., and Hunt, J. C. (1967). Nephrotio syndrome with use of ammoniated mercury. Archives of Internal Medicine, 120, 581.

Stock, A. (1926-40). Cited in Trace Elements in Food, pp. 453-468ब By G. W. Monier-Williams. Chapman and Hall, London? 1949.

Van Zeijst, J. A. M., Arends, A., and Mandema, E. (1964). Mogelijke complicaties bij kwiktherapie. Nederlandsch Tijdschrift voor Geneeskunde, 108, 1381.

Warkany, J., and Hubbard, D. M. (1948). Mercury in the urin $\vec{E}$ of children with acrodynia. Lancet, 1, 829. , and Hubbard, D. M. (1953). Acrodynia and mercury Fournal of Pediatrics, 42, 365.

Wild, R. B., and Roberts, I. (1926). The absorption of mercurials from ointments applied to the skin. British Medical fournalf $1,1076$.

Young, E. (1960). Ammoniated mercury poisoning. Britis fournal of Dermatology, 72, 449.

Correspondence to Dr. Peter Husband, Fulhamb Hospital, London W.6. 